\title{
Emotional Intelligence: Soft Skills Training Curriculum, an Educational Training for Healthcare Students for Increased Success during Clinical Rotations
}

\section{Thomas J*, Adames S, Gonzales A, Milina E and Zhao G \\ Department of Occupational Therapy, SUNY Downstate Medical Center, USA}

*Corresponding author: Jasmin Thomas, Department of Occupational Therapy, SUNY Downstate Medical Center, 450 Clarkson Ave, Brooklyn, NY 11203, USA, Tel: 718-270-7733; Email: Jasmin.Thomas@downstate.edu

\section{Research Article \\ Volume 2 Issue 3}

Received Date: June 25, 2019

Published Date: August 05, 2019

DOI: $10.23880 /$ aphot-16000135

\section{Abstract}

Emotional intelligence (EI), or soft skills, is a set of skills including professionalism, effective communication skills, organizational skills, and responsivity to feedback. Research indicates that healthcare students entering their clinical rotations may lack these sets of skills The lack of soft skills during clinical experience can strain the student's professional relationship with their clinical educators/instructors (supervisors) and may result in failure After a review of relevant literature, the purpose of this research project is to augment the evidence-based, soft skills training curriculum being developed at SUNY Downstate Medical Center Occupational Therapy Master's Program through the production of three educational videos that incorporate the perspectives of clinical educators, alumni, and current students. The goal of the project is to increase students' knowledge of emotional intelligence and inspire self-awareness and reflection on their own professionalism. The curriculum would ideally function to increase students' success during clinical rotations and develop more competent clinicians. The curriculum was piloted with second year occupational therapy students prior to their clinical rotations. The curriculum educated students on soft skills and promoted reflection on their own professionalism. The curriculum findings demonstrated significant outcomes with students reporting the use of emotional intelligence skills during clinical rotations to be valuable. The findings of this study indicate that the need for emotional intelligence training may also be applicable and valuable to students in various healthcare programs.

Keywords: Emotional Intelligence; Soft Skills; Fieldwork; Occupational Therapy; Clinical Rotations; Clinical Education

\section{Introduction}

An individual's level of emotional intelligence within the context of clinical practice can produce a successful therapeutic relationship between the therapist and client. Emotional intelligence can also influence one's ability to work with other health professionals and their supervisors. Brown, Williams, and Etherington [1], found 
that factors such as emotional awareness of others, emotional reasoning, and emotional management were significant predictors of occupational therapy student success during clinical rotations [2,3].

Research found that communication, time management and teamwork were valued soft skills for competency [4]. As few opportunities exist to foster the development of these attributes during traditional healthcare programs, a curriculum teaching emotional intelligence would be beneficial to the development of emotional intelligence prior to students beginning clinical rotations and, therefore, improving the likelihood of a successful experience for the student and clinical educator.

By improving the student-supervisor relationship through learned emotional intelligence skills, students can increase their learning, confidence, and competency as they progress through clinical rotations and transition into being clinicians. Correspondingly, a curriculum aimed at clinical educators, such as delivering feedback and how to maintain a successful relationship with the student is also valuable and can be included within educational training curriculum goals as well.

\section{Methods}

Clinical educators were provided questionnaires regarding their perspectives on emotional intelligence and the use of emotional intelligence by students during Level II Fieldwork. 45 clinical educators from various clinical settings responded and their feedback was analyzed using mix-methods.

Of the clinical educators that responded, 38 out of 45 , or 84 percent, reported practicing emotional intelligence as a clinician to be very important. 37 out of 45 , or 82 percent, reported a student's emotional intelligence during fieldwork to be very important. Lastly, 32 out of 45 , or 71 percent, reported that emotional intelligence should be implemented into occupational therapy curriculum. These responses support the value and need for an emotional intelligence training curriculum in preparation for students' clinical rotations.

In addition to these questions, clinical educators were asked to report instances in where emotional intelligence was or were not demonstrated in their clinical practice. These responses were coded for specific soft skills and outlined in Figure 1. This data was then used to develop the scripts and discussion questions for the video vignettes that were included in the training curriculum. Incorporation of the clinical educators' feedback into the video production served to augment the legitimacy of the videos' content.

\begin{tabular}{|c|c|c|}
\hline $\begin{array}{c}\text { Emotional } \\
\text { Inteligence/Soft Skill }\end{array}$ & Demonstarted & Lacked \\
\hline Open Mindedness & 3 & 0 \\
\hline Emotional Regulation & 6 & 0 \\
\hline Team Work & 2 & 0 \\
\hline $\begin{array}{c}\text { Open verbal } \\
\text { Communication }\end{array}$ & 14 & 6 \\
\hline $\begin{array}{c}\text { Non Open verbal } \\
\text { Communication }\end{array}$ & 3 & 1 \\
\hline $\begin{array}{c}\text { Empathy (Sensitive to } \\
\text { clints's nedds) }\end{array}$ & 23 & 6 \\
\hline Professional Conduct & 10 & 0 \\
\hline Compromise & 3 & 1 \\
\hline Flexibility & 5 & 2 \\
\hline Patience & 4 & 1 \\
\hline Positve Attitude & 3 & 2 \\
\hline Unprofessional Conduct & 0 & 16 \\
\hline $\begin{array}{c}\text { Poor self and emotional } \\
\text { regulation }\end{array}$ & 0 & 14 \\
\hline Responsively to feedback & 5 & 4 \\
\hline
\end{tabular}

Figure 1: Emotional intelligence soft skill.

The vignettes were designed, developed, and produced following an evidenced-based approach. The following scenarios featured in the vignettes were developed using data collected through an extensive literature review and feedback from alumni and clinical educators collected through quality assurance surveys. The vignette entitled "Mindfulness of Emotions" highlights the importance of emotional regulation, sensitivity to client's needs, professional conduct, and verbal communication skills, "Friendly but not Friends" highlights the importance of integrity, responsibility, professional conduct, and verbal communication skills, "Confidence in the Clinic" highlights the importance of flexibility, open mindedness, responsivity to feedback, and verbal communication. Each vignette is accompanied by a suggested list of questions to promote group discussion on interactions portrayed in the short film.

The curriculum was designed to promote active learning and included viewing of three video vignettes, question directed group discussion, and role play activities. Thirty second-year occupational therapy students participated in the emotional intelligence training curriculum. Prior to and following participation 


\section{Annals of Physiotherapy \& Occupational Therapy}

in the curriculum, pre- and post-test surveys were administered to students to gauge their knowledge of emotional intelligence, as well as perspectives on the use of emotional intelligence during fieldwork in regards to the supervisor-supervisee relationship and its impact on fieldwork success. Of the thirty occupational therapy students who participated in the curriculum, all thirty responded to both the pre- and post-test surveys.

\section{Results}

The analyzed data demonstrated that the curriculum was impactful. As shown in Table 1, with an alpha of 0.5, the Mann-Whitney U test indicated that the knowledge of emotional intelligence as reported by participants' preand post-test results showed a significant increase after participating in the curriculum, $\mathrm{U}=179.0, \mathrm{p}=.00$.

\begin{tabular}{|c|c|c|c|c|}
\hline \multicolumn{5}{|c|}{ Mann-Whitney Test } \\
\hline \multirow{3}{*}{ Source } & Ganks & N & Mean Rank & Sum of Ranks \\
\cline { 2 - 5 } & Proup & 30 & 24.47 & 644.00 \\
\cline { 2 - 5 } & Post & 30 & 39.53 & 1186.00 \\
\cline { 2 - 5 } & Total & 60 & & \\
\hline \multirow{4}{*}{ Test statistices } \\
\hline \\
\cline { 2 - 5 } & Mann-Whitney U & 179 & & \\
\cline { 2 - 5 } & Wicoxon W & 644 & & \\
\cline { 2 - 5 } & Z & -4.451 & & \\
\cline { 2 - 5 } & Asymp.Sig. (2-tailed) & .000 & & \\
\cline { 2 - 5 } & Exact Sig. (2-tailed) & .000 & & \\
\cline { 2 - 5 } & Exact Sig. (1-tailed) & .000 & & \\
\hline
\end{tabular}

Table 1: Mann-Whitney Test $U=179.0, p=.00$.

a. Group of variable: Group

As shown in Table 2, an alpha of .05, the MannWhitney $\mathrm{U}$ test indicated that the importance of practicing emotional intelligence when developing a professional relationship with the clinical supervisor reported by participants' pre- and post-test results showed a significant increase, $\mathrm{U}=845.0, \mathrm{p}=0.27$.

\begin{tabular}{|c|c|c|c|c|}
\hline \multicolumn{5}{|c|}{ Mann-Whitney Test } \\
\hline \multicolumn{5}{|c|}{ Ranks } \\
\hline \multirow{4}{*}{ Source } & Group & $\mathbf{N}$ & Mean Rank & Sum of Ranks \\
\hline & Pre & 30 & 28.17 & 845.00 \\
\hline & Post & 30 & 32.83 & 985.00 \\
\hline & Total & 60 & & \\
\hline \multicolumn{5}{|c|}{ Test statistices $^{\mathbf{a}}$} \\
\hline & Mann-Whitney U & 380.00 & & \\
\hline & Wicoxon W & 845.00 & & \\
\hline & $\mathrm{Z}$ & -1.376 & & \\
\hline & Asymp. Sig. (2-tailed) & .169 & & \\
\hline & Exact Sig. (2-tailed & .233 & & \\
\hline & Exact Sig. (1-tailed & .116 & & \\
\hline & Pont Probability & .027 & & \\
\hline
\end{tabular}

Table 2: Mann-Whitney Test $U=845.0, p=0.27$.

a. Group of variable: Group

Following the curriculum, as seen in Figure 2, more students reported practicing emotional intelligence skills during fieldwork to be very important, with an increase from 23 to 26 students. As seen in Figure 3, more students also felt that their relationships with their clinical supervisors and its impact on fieldwork success were very important as there was an increase from 20 to 24 students. As seen in Figure 4, more students also felt that 
practicing emotional intelligence when developing a professional relationship with their clinical supervisor was very important as that number increased from 20 to 25 students.

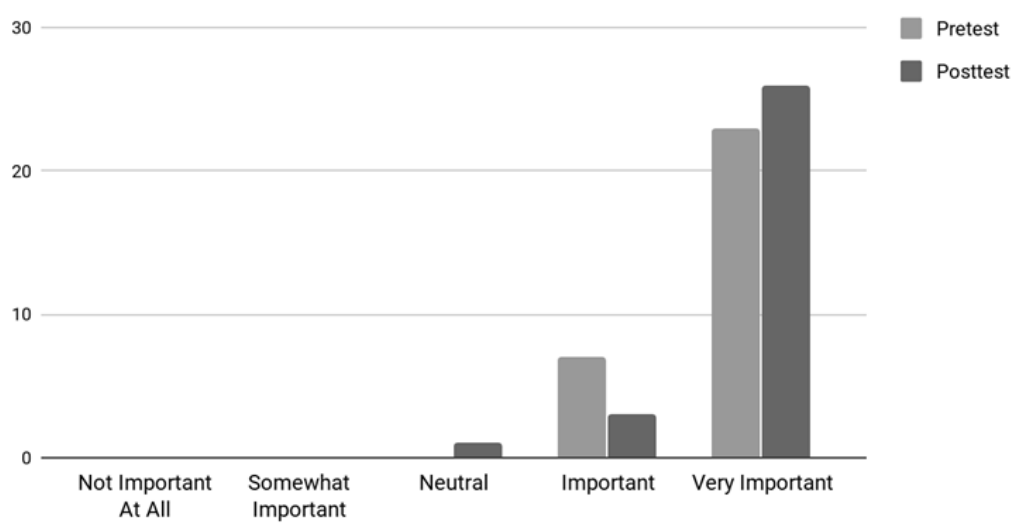

Figure 2: How important do you think it is to practice emotional intelligence skills during fieldwork?

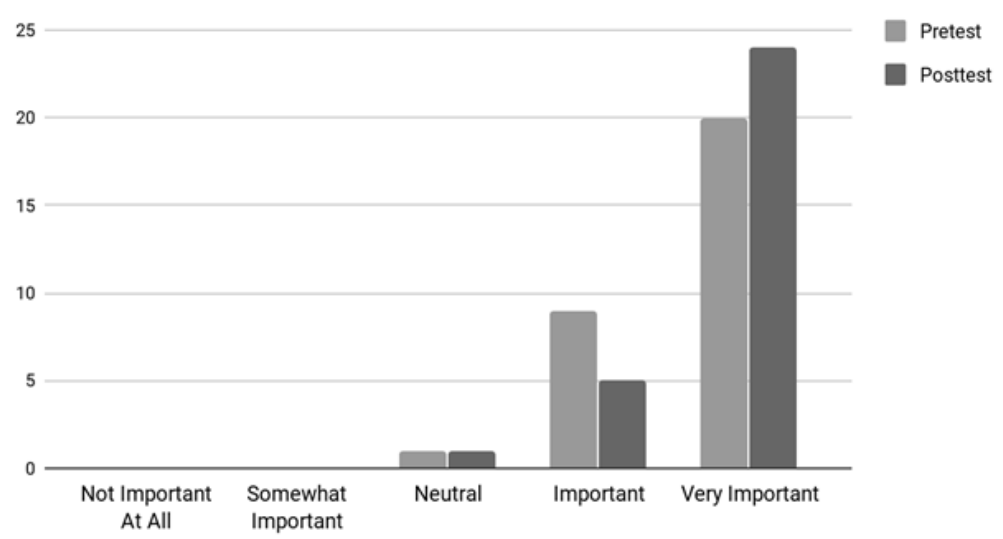

Figure 3: How important do you think your relationship with your clinical supervisor is for your success in fieldwork?

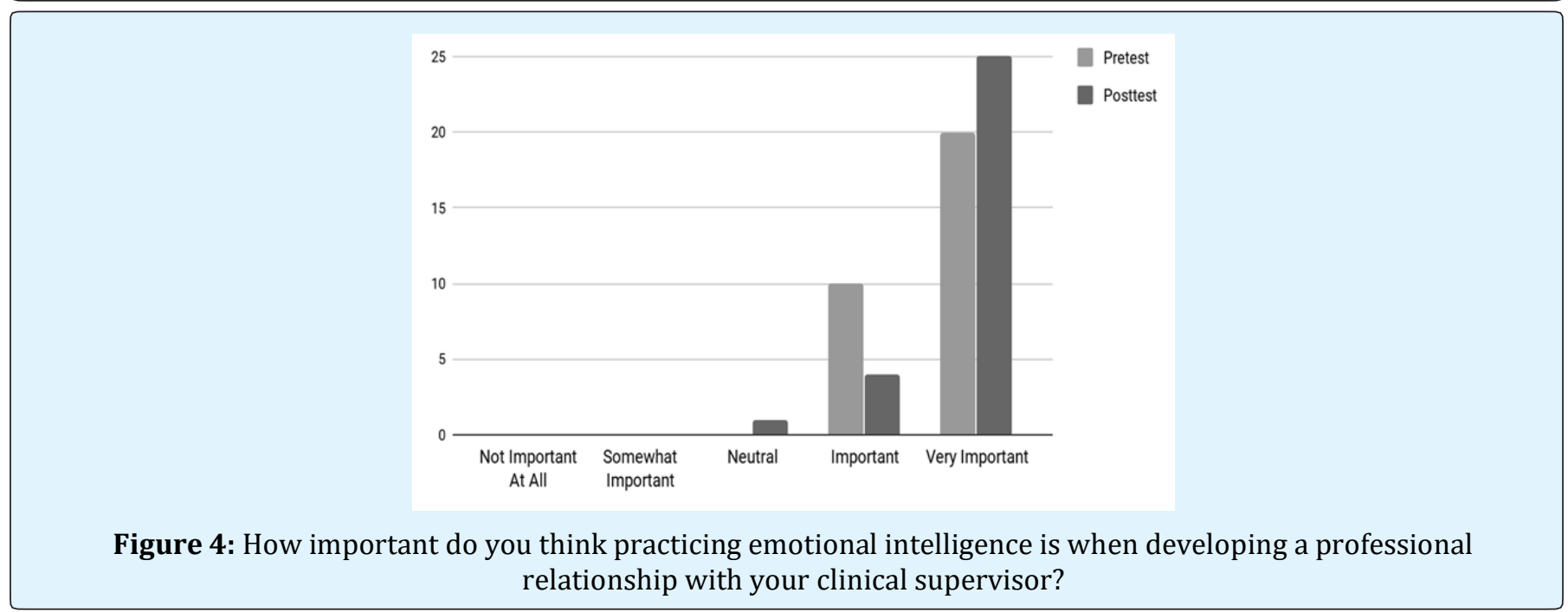




\section{Annals of Physiotherapy \& Occupational Therapy}

Speaking to the value of the presented curriculum material, 100 percent of students surveyed found the video vignettes to be relatable and interesting. Lastly, as seen in Figure 5, 96 percent, or 29 out of 30 students, responded that the curriculum was effective in enhancing their emotional intelligence or soft skills.

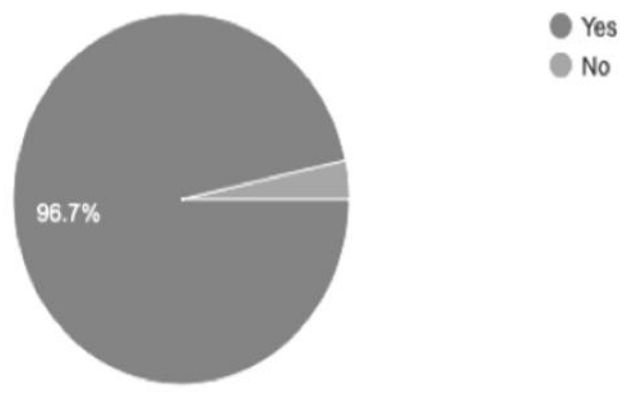

Figure 5: Speaking to the value of the presented curriculum material, 100 percent of students surveyed.

\section{Limitations}

The participants had only engaged in two Level I Fieldwork rotations and had yet participated in Level II Fieldwork. This may limit the extent to which the participants retain the information and skills gained during the curriculum. Follow-up data should be collected after the participants complete their Level II Fieldwork in order to gauge whether they applied the curriculum and found it beneficial in these experiences.

The pilot program was initially conducted with occupational therapy students, it would be beneficial to include students from other healthcare professions to broaden the reach of the curriculum.

\section{Conclusion}

These preliminary findings support the value of the developed emotional intelligence curriculum and encourage its use in the training of occupational therapy students in preparation for their Level II Fieldwork experiences. Although the study was conducted with occupational therapy students, research indicates that students in other healthcare professions would also benefit from participating in an emotional intelligence training before commencing their clinical rotations.
Emotional intelligence and its value in the training of future healthcare professionals have been examined across various healthcare professions. The benefits of incorporating an emotional intelligence training curriculum into the education of healthcare professionals extend beyond a single discipline. Irfan, Saleem, Sethi, Abdullah [5] found a strong correlation between empathy and emotional intelligence in medical and dental students. This study identified a need to work on the emotional intelligence skills of students to improve their empathetic behavior. Grant, Kinman, and Alexander [6] examined the effects of a workshop on increasing the reflective ability and empathy in social work students. Significant results were found in the students who participated in the workshop. Shahbazi, Heidari, Sureshjani [7,8] identified the potential of improving nursing student's problemsolving and personal skills in order to increase the quality of services and overall client satisfaction. These developments in research continue to highlight the growing demand for emotionally intelligent healthcare professionals. Incorporating emotional intelligence training into healthcare education has the potential to improve the quality of interpersonal and inter professional interactions within healthcare settings and may ultimately improve patient-centered care.

The Emotional Intelligence Curriculum is located on SUNY Downstate Medical Center's web page, which includes videos, discussion questions and roleplay suggestions:

https://www.downstate.edu/chrp/ot/resources/emotion al-intelligence/index.html. The curriculum is designed to be accessed and modified for the needs of various healthcare programs. The findings suggest that the curriculum would be an effective tool and it may be appropriate to disseminate to other healthcare programs in order to expand the number of participants and advocate for the value of emotional intelligence training during formal education. Emotional intelligence training is not only valuable, but essential in building competent future clinicians.

\section{References}

1. Brown T, Williams B, Etherington J (2016) Emotional intelligence and personality traits as predictors of of occupational therapy students' practice education performance: A cross-sectional study. Occup Ther Int 23(4): 412-424. 
2. James KL, Musselman L (2006) Commonalities in level II fieldwork failure. Occup Ther Health Care 19(4): 67-81.

3. Naidoo D, Wyk JV (2016) Fieldwork practice for learning: Lessons from occupational therapy students and their supervisors. African Journal of Health Professions Education 8(1): 37-40.

4. Wallingford M, Knecht-Sabres LJ, Lee MM, Stamand LE (2016) OT practitioners' and OT students' perceptions of entry-level competency for occupational therapy practice. The Open Journal of Occupational Therapy 4(4): 10.

5. Irfan M, Saleem U, Sethi MR, Abdullah AS (2018) Do we need to care: Emotional intelligence and empathy of medical and dental students. Journal of Ayub Medical College Abbottabad 31(1): 76-81.
6. Grant L, Kinman G, Alexande K (2014) What's all this talk about emotion? Developing emotional intelligence in social work students. Social Work Education 33(7): 874-889.

7. Shahbazi S, Heidari M, Sureshjani EH, Rezaei P (2018) Effects of problem-solving skill training on emotional intelligence of nursing students: An experimental study. J Edu Health Promot 7: 156.

8. Brown T, Williams B, Etherington J (2016) Emotional Intelligence and Personality Traits as Predictors of Occupational Therapy students Practice Education Performance: A Cross-Sectional Study. Occupational Therapy International 23(4): 412-424. 